\title{
A Study on the Adaptability to the Elders of Nursery for the Aged in
}

\section{Indiscrete Space}

\author{
$\mathrm{Xu} \mathrm{Wei}{ }^{1, a}$ and Li Yajun ${ }^{2, b}$ \\ ${ }^{1}$ Nanjing University of Science and Technology, Nanjing, Jiangsu Province, P.R.C. \\ ${ }^{2}$ Nanjing University of Science and Technology, Nanjing, Jiangsu Province, P.R.C. \\ aForever608@163.com, blyj5088@163.com
}

\section{Keywords: Indiscrete Space, Nursing Home, Adaptability to the Elders}

Abstract. Discussions on community \& multi-function-based aged care in China are mostly converged on and manifested as follows, (1) The "software" level as in policies, models, industry and even management instead of the "hardware" studies as in the living space of the elders where a hierarchy system and well-thought-out opinions are absent; (2) Fearful tendency of administerization and institutionalization. Especially the construction of facilities for the elders is mostly oriented by the "top-down" subjective analysis and evaluation. Studies on the aged-users-centric Post Occupancy Evaluation (POE) of existing community-based nursing homes still remain insufficient, and there is a lack of an evaluation system of infrastructure for the elders' adaptability to their living conditions. An advocacy shall be called upon everyone in China for concerted efforts in studying how to improve the adaptability of services for the aged to the space of facilities, and providing the elders with an easeful and upbeat living environment. Based on the fundamental principle of "Aging in Place" of the adaptability of the living conditions of nursing homes, this paper presents a humble opinion regarding the ideas of space design from the perspectives of safety, comfort and positivity, and hopefully provides a foundation for the discussions of the likes of such studies.

\section{Motivation \& Objective}

\section{Social Phenomenon}

An increasingly aging society with Chinese characteristics: Aging of population has been on an acceleration worldwide, and bears down even more aggressively on China, making China "get old before getting rich and get old unprepared". For one thing, China has a large population base of nearly 1.4 billion of which the elders above 65 years old account for $8.87 \%$; for another, the " $4+2+1$ " family structure becomes pervasive in society after almost 4 decades of the One-Child Policy, which expedited the advent of an aged China. By 2030, the population of the elders above 65 years old is expected to exceed 230 million, according to Deutsche Welle, which is a tripled number of the total population of Germany.

Psychological contradictions and embarrassing situation: Psychological contradictions mostly occur to the elders who, on the one hand, wish for "the accompanying of children and grandchildren for twilight years of jubilance"; on the other hand, they do not wish to cumber their children who are already stressful in life. Embarrassing situation means that those middle-aged or young couples who are willing to perform their filial duties yet become heavy-laden from doing so, whether the stress from the competition in the workplace and society, or the needs to care for the elders and their own children, all of which make them feel torn between all these things. The 
number of the spouse-bereft elders who live in solitude has been on an annual rise. Statistics show that there are nearly 1,400 disabled and dementia-related old people going missing every day in China.

Attention from all social sectors, and increase of number yet poor quality: Care for the aged is a "focus issue" in China nowadays, and whether the Chinese government or every social sector is paying high attention on the aging of population and figuring out countermeasures. The government has implemented a series of macro policies on a governmental level and micro measures on a social level for the system of elderly care, and certain preliminary results have already been achieved: Up to the end of 2013, as indicated by the statistics of the Ministry of Civil Affairs, there are 54,000 schools for senior citizens with 6.92 million students, and 360,000 activities rooms for the aged; there are 42,475 nursing institutions for the aged of all sorts across China with 4.937 million beds, among which there are 641,000 beds for staying in communities and daytime care. It is an irrefutable fact that the "number" is on a rise, but the "quality" of services is still groping about in the dark demanding prompt improvement.

\section{National Policies}

In the "12th Five-Year Plan" for the Construction of the Social Elderly Care Services System issued by the Ministry of Civil Affairs of China in 2011, the idea of "a home-based, community-dependent and institution-supported social elderly care services system" was proposed for the first time, and a community care index which requires for "30 beds among every thousand senior citizens" was put forward as well. Whereafter, the Ministry of Civil Affairs elaborated the proportions in respect of care services provided at home, community and institution, which are $90 \%$, $7 \%$ and 3\%, a policy that was later abbreviated as the "9073" National Policy.

On May 27th 2016, the Politburo of the CPC held the 32nd collective learning concerning the situation and countermeasures of the aging population problem in China. During the conference, the General Secretary of the CPC Central Committee Xi Jinping emphasized that all citizens shall be mobilized, and the satisfaction of the needs of the elders shall be combined with the solution of the aging population problem. Meanwhile, the advantages and opportunities brought by an aging population to the country's development shall be fully exploited, and the ever-increasing physical and mental needs of the elders shall be met, realizing a well-coordinated and sustainable development of the cause of aging. Li Keqiang, the Premier of the State Council also pointed out that the aging population problem has to be coped with in a scientific mode of thinking, and relevant policy proposals shall be promptly studied and proposed in line with the making and implementation of the "13th Five-Year Plan", while the operability must be taken into consideration as well. In November 2016, the policy of The Notice concerning the Launch of the Reform Experimentation of Home-Based and Community-Based Elderly Care Services Supported by the State Revenue was jointly issued by the Ministry of Civil Affairs and the Ministry of Finance, indicating the great support from the government to the multi-level elderly care services system that is home-based, community-dependent, and institution-supported with the combination of medical services and care services. Governments at all levels are now in the discussion and exploration of issuing hard-and-fast rules regulating the ancillary facilities for elderly care in both new and old communities, of which the scale is dependent on the local aged population.

\section{Practical Experiences}

The dynamic development of community elderly care services model is being actively explored and promoted all over China. Investigations revealed that whether the fact that almost $90 \%$ 
of senior citizens prefer the idea of Aging in Place, or the social care for the elders provided by younger generations and the "respite" care services, or the technical support provided by big data and intelligent applications, community elderly care services always comply with traditional family values in the east, and more adaptable to the tendency as families are downsizing in modern times.

With the shift of the concept of child-bearing in China, and the forming of the 4:2:1 structure (namely two couples of the elders +1 husband and 1 wife +1 single child), the possibility that the elders are taken care of solely by immediate family members (mainly the children of the elders) is becoming progressively lower, and the proportion of the elders and elderly couples who live independently is rising, suggesting an increasing demand for social care.

\section{Definitions}

\section{Small Scale Nursing Home in an Indiscrete Space}

"Small scale nursing home in an indiscrete space" is a term originated from Japan, a type of nursing homes that has been attached with importance in construction since 2011. The so-called "indiscrete space" means geographical closeness to community. Such policy suggests the construction of small scale nursing homes for the elders with less than 29 beds in an area of no more than 40,000 aged population. The concept, which is being actively promoted in Hong Kong, Macau and Taiwan, has evolved to a term that means community nursing homes for the aged population of certain regions. Unlike regular nursing homes that are open to the entire society, "nursing homes in an indiscrete space" are only open to the elders who live within or next to a certain region. Such "one bowl of soup away" elderly care services are especially suitable for the overall needs of senior citizens in a "Confucianism" culture background.

\section{"Aging in Place"}

The idea of "Aging in Place" [1] was first derived from the concept of "local aging" proposed by Doctor Airy Bogueglan from Sweden in 1965, which means the home extends its function from a place of residence (living) to a place of living functions (community). Therefore, the "Aging in Place" is interpreted in this paper as: The elders stay in their own homes or a familiar environment of choice to age, and may receive family care, healthcare, and other professional care services from local communities so that they may live an independent and dignified life. Especially when an old adult becomes weak, ailing or handicapped, he or she may stay at home as long as possible with the support of necessary services, or settle down in a nursing home of local community in order to live in a familiar and friendly environment without leaving his or her families and friends as well as the living environment for long-term care. There are 3 models of aging in place areas which are illustrated in Table 1. 
Table 1. Models of aging in place areas

\begin{tabular}{|c|c|c|c|c|c|}
\hline \multicolumn{5}{|c|}{ Newly built community } & $\begin{array}{l}\text { Built-in in original living } \\
\text { communities }\end{array}$ \\
\hline & 1 & $\begin{array}{l}\text { Urban-suburban } \\
\text { separated }\end{array}$ & 2 & $\begin{array}{l}\text { Complex in new } \\
\text { urban district }\end{array}$ & 3 On-the-spot \\
\hline $\begin{array}{l}3 \\
\frac{3}{2} \\
\frac{2}{0}\end{array}$ & & $\begin{array}{l}\text { cated in rural areas } \\
\text { scenic spots of } \\
\text { asant natural } \\
\text { vironment, together } \\
\text { th independent } \\
\text { dical facilities for } \\
\text { lerly care services. }\end{array}$ & & $\begin{array}{l}\text { sidential quarters for the } \\
\text { ers designed and } \\
\text { eloped in new urban } \\
\text { elopment areas, } \\
\text { ether with activities } \\
\text { ters, daytime care, } \\
\text { dical service } \\
\text { titutions and elderly } \\
\text { e facilities of other } \\
\text { ms }\end{array}$ & $\begin{array}{l}\text { Elderly community built in } \\
\text { existing residential } \\
\text { quarters so that the elders } \\
\text { may still use the public } \\
\text { facilities within the } \\
\text { quarter. }\end{array}$ \\
\hline 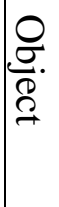 & & ders only & & $\begin{array}{l}\text { itude elders or aged } \\
\text { hilies of different } \\
\text { erations }\end{array}$ & $\begin{array}{l}\text { Residents of different ages } \\
\text { share the same living } \\
\text { quarter }\end{array}$ \\
\hline 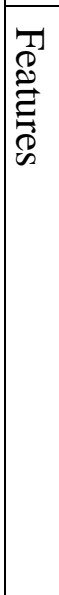 & & $\begin{array}{l}\text { e elders have to } \\
\text { ive their familiar } \\
\text { ing environment } \\
\text { cause the } \\
\text { oan-suburban } \\
\text { parated model is far } \\
\text { m the living circle } \\
\text { urban residents, and } \\
\text { orings considerable } \\
\text { pact on the social } \\
\text { e of the elders. }\end{array}$ & & $\begin{array}{l}\text { from the living circle } \\
\text { urban residents, and } \\
\text { ited social groups for } \\
\text { elders. }\end{array}$ & $\begin{array}{l}\text { The connections between } \\
\text { the elders and their } \\
\text { families and friends can be } \\
\text { maintained, ensuring that } \\
\text { the elders still live in a } \\
\text { familiar environment. The } \\
\text { so-called One Bowl of } \\
\text { Soup Away filial piety. }\end{array}$ \\
\hline \multicolumn{3}{|c|}{ Sense of abandonment } & & vironmental strangeness & Sense of belonging \\
\hline
\end{tabular}

\section{Theories \& Methods}

\section{Relevant Studies Regarding the Adaptability to the Elders of Space}

Studies of adaptable environment and facilities to the elders have a long-standing history, whether in foreign countries or China. Relevant studies emerged in western developed countries as early as 1950s, but most of them were merely discussions regarding models and buildings: In 1999, Robert Schafe discussed the demands of American senior citizens for supportive services and facilities in his paper America's Elderly Population and Their Needs for Supportive Services. Those elders who are healthy, capable of self-care and semi-capable of self-care may choose assorted individual or collective services according to their economic and physical conditions. American scholars Michael et al. have studied and designed a model of hierarchic elderly care facilities in their paper Location of Service Facilities for the Elderly. Such hierarchic supportive and care 
service facilities may provide life care services of multiple levels and types; in Japan, the government is still unable to house all elders due to the heavy payments in infrastructure construction and social welfares, hence the proposal of community service network, which is a new symbolic type of welfare facilities known as the "small scale and multi-functional accommodations" that provide all-round convenient services for aging in place care, and cover regular communities in a network-like form; in China, after data analysis of investigations in a number of cities, many scholars have found out that establishing and perfecting facilities that meet daily needs in communities, including facilities of catering services, door-to-door services and care services, proved to be an appropriate method of care in order to meet the various needs in life of the elders. The studies of elderly care service facilities are increasing both in China and other countries, but studies that focus on the use of senior citizens, plan and design space from the perspectives of dynamic and differentiated needs still remain rarely seen.

The following Fig. 1 and Table 2 demonstrate framework of this research after the review of relevant literatures. Based on various "user-centric" methods, this research mainly investigated several "indiscrete" and "built-in" community nursing homes in Beijing, Shanghai, Nanjing and Taiwan of China, as well as Japan, and the natures of the elders being nursed, number of people, activities, care modes and ideas were recorded, and their space arrangement, functional circulation, and layout of facilities were photographed and portrayed, and certain construction inspirations were achieved.

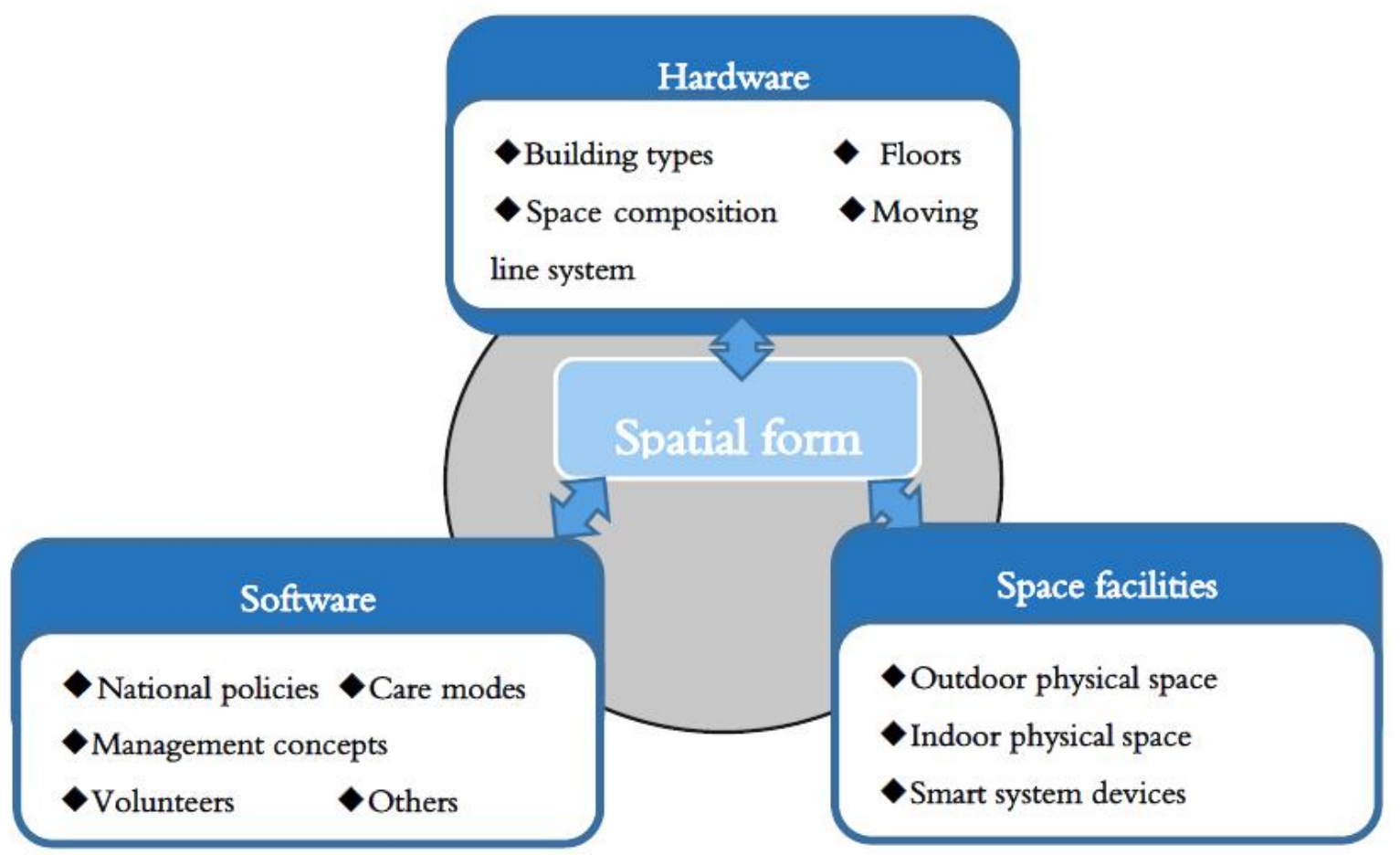

Fig.1 Research framework 
Table 2. Key research objects (grey area)

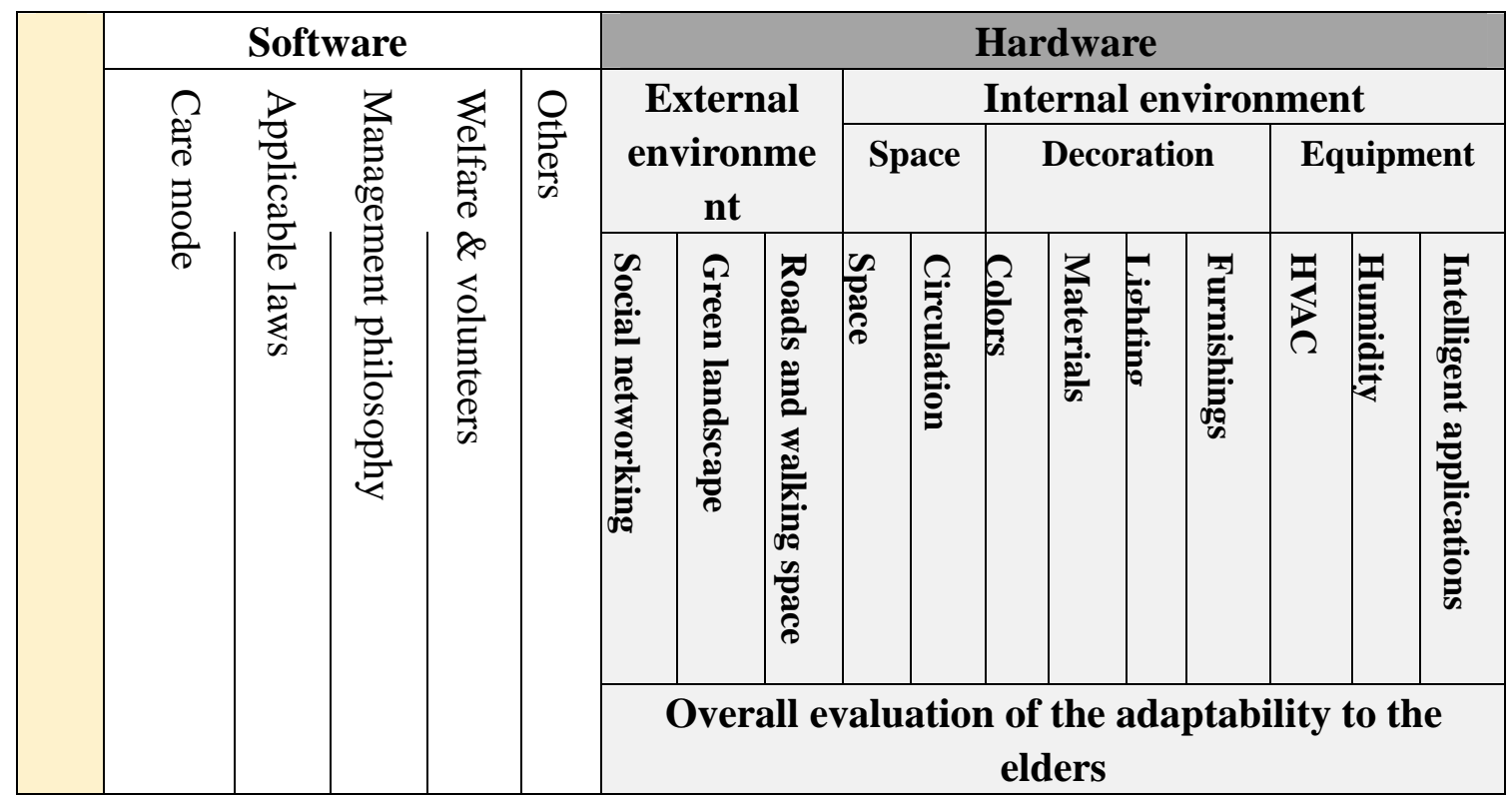

\section{Suggestions for the Adaptability to the Elders of Nursing Homes in an Indiscrete Space}

This paper puts the emphasis on the study of the adaptability to the elders of the space of built-in nursing homes in the aging in place mode, of which the features are small scale and built-in. Thus, the following part will focus on the discussing of the space structure and the suggestions for adaptability to the elders of indiscrete nursing homes in original living communities.

\section{Understanding of the Conditions and Needs of the Elders}

The user-centric-based adaptability to the elders design of community space requires discussion of the positive and negative influential factors of space and the activities of senior citizens from the perspectives of the elders themselves, the space arrangement and equipment. The elders themselves are indeed a research object of incredible complexity whose conditions of bodily functions, behavior characteristics, composite demands, behavior patterns and areas shall be promptly clarified (please refer to Fig.2 and Table 3 ).

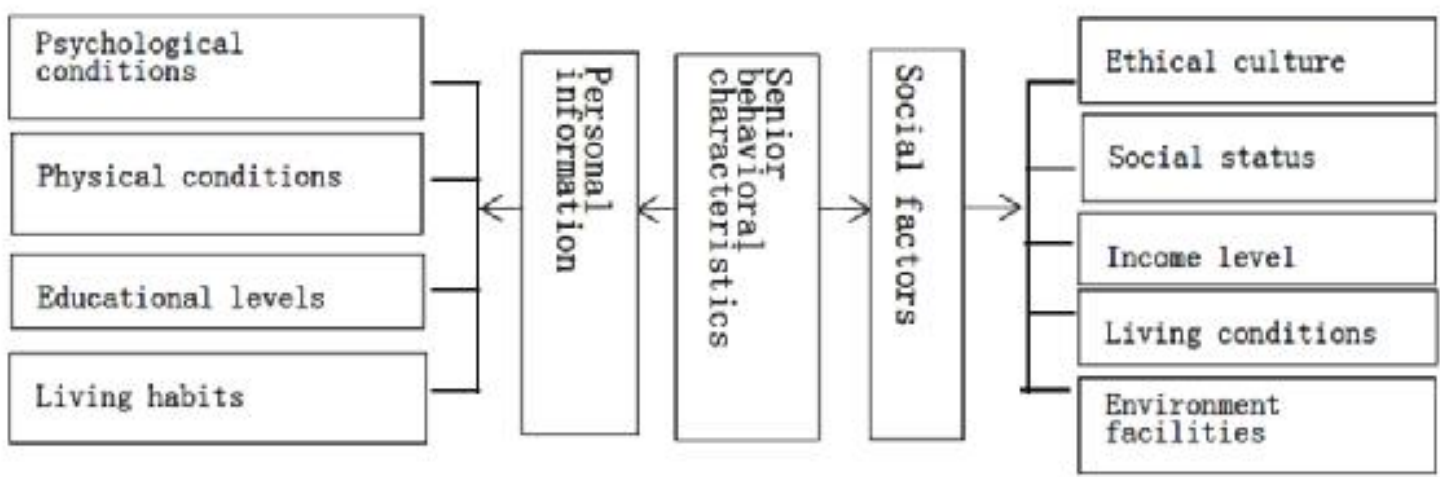

Fig.2 Factors that affect the behavior characteristics of the elders 
Table 3. The basic conditions and needs of the elders in the community

\begin{tabular}{|c|l|c|}
\hline Type & \multicolumn{1}{|c|}{ Conditions } & \multicolumn{1}{c|}{ Needs } \\
\hline $\begin{array}{c}\text { Capable of } \\
\text { self-care }\end{array}$ & $\begin{array}{l}\text { Physically healthy, and capable of independent living and } \\
\text { self-care. }\end{array}$ & $\begin{array}{c}\text { Participation in community } \\
\text { recreational events, no } \\
\text { accommodation needed }\end{array}$ \\
\hline $\begin{array}{c}\text { Instruments } \\
\text { needed }\end{array}$ & $\begin{array}{l}\text { Basically healthy, slightly difficult in moving, incapable of } \\
\text { independent self-care in daily life, and aids from } \\
\text { instruments and nursing staff needed }\end{array}$ & $\begin{array}{c}\text { Periodical accommodation, } \\
\text { supporting elderly care, } \\
\text { selective participation in } \\
\text { rehabilitation and }\end{array}$ \\
\hline Care needed & $\begin{array}{l}\text { Poor health conditions, difficult in moving, incapable of } \\
\text { self-care, and medical care needed for daily life }\end{array}$ & $\begin{array}{c}\text { Long-term and targeted } \\
\text { accommodation and care, } \\
\text { and medical services needed }\end{array}$ \\
\hline
\end{tabular}

\section{Site Selection and Allocation of Nursing Homes}

Nursing homes shall remain close to all sorts of existing ancillary facilities in the community such as facilities of medical and emergency services, sports and fitness, culture and entertainment, catering services, supermarkets, and management, as well as pedestrian walkways that connect these facilities. Because the maximum radius of action of healthy elders is usually 450 to 500 meters, it is ideal to arrange the above mentioned functional facilities within such range. Nursing homes have higher requirements for noise environment, visual environment and green environment than those of surrounding residential quarters. As for noise environment, nursing homes shall be located away from urban main roads, expressways and high-speed railways, and light railways. Meanwhile, various entertainment places that tend to produce noise pollution shall be avoided. As for visual environment, the accessibility of sight shall be ensured, and the buildings and surrounding roads shall be of conspicuous identifiability.

The layout of elderly care service facilities in the community shall be arranged differently according to the distribution of the aged population, and such layout shall take the walking distance of the elders and the frequency of utilization into consideration too (please refer to Fig. 3).

With the sorting of literatures and case investigations, it has been found out that the current arrangement of community nursing homes is mainly guided by subjective qualitative analysis: As in, several experts are invited during the construction of community or the review or assessment period of project bidding to carry out their subjective qualitative analysis with their profound professional knowledge and practical project experiences, in order to conclude a preferred embodiment or a subjective and qualitative guidance regarding the project. Such method is easy and convenient, which makes it fairly applicable when the evaluation objects and influential factors are relatively fewer; nevertheless, it appears less objective, accurate or even feeble when assessing the adaptability needs of the elders in case of too many evaluation objects and complicated relations among the influential factors. In that case, the elderly users shall be seen as the center, and all decision makers and performers shall uphold the attitude of service design, and integrate all kinds of resources and assistances, such as inviting users to be involved in the design in early stage, conducting Post Occupancy Evaluation (POE) for similar facilities, and interviewing with senior designers; in addition to traditional constructivist approach which is used to elaborate the complicated geometric figures in a space system, other scientific approaches such as the "space syntax theory" of the quantitative data system which are safe, accessible, diversified, fault-tolerant, and comfortable can be adopted for the project implementation (please refer to Fig.4). 

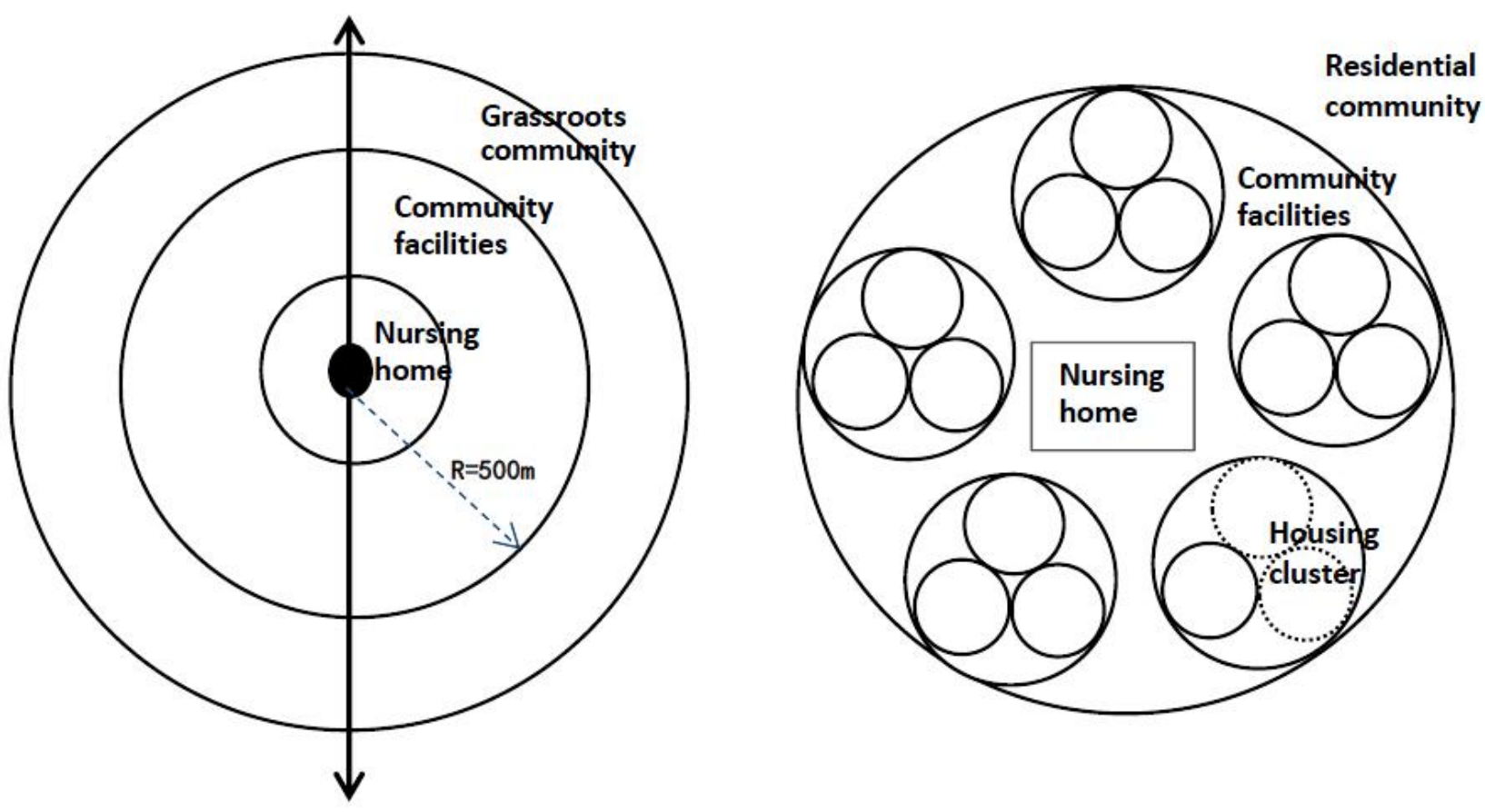

Fig.3 General view of the locations of nursing home service facilities

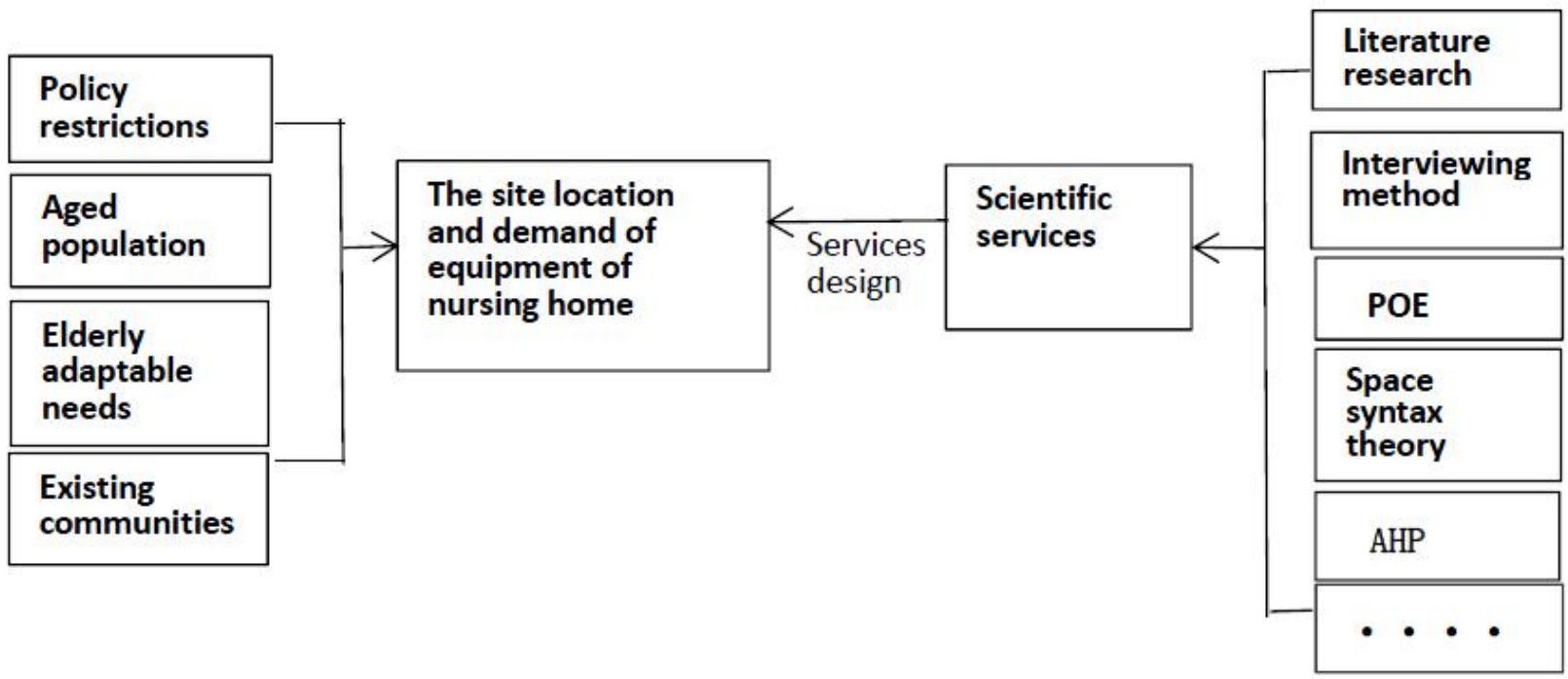

Fig.4 Ideas of the site location of nursing homes

\section{Suggestions for the Adaptability to the Elders of the Original Living Communities}

The original meaning of aging in place is that, first, the elders live at home, and second, encourage people to move the elders to continuous care facilities they preferred when they are healthy. Continuous care mode provides care services from life support, care, dementia-related period and palliative period services, creating a feeling of home with more and more time being devoted in care communities so that senior citizens may spend their remaining years peacefully in a familiar environment. Place experiences are the result of the interaction between people and a physical environment ${ }^{[2]}$. The stimulation, accessibility, crowdedness, privacy, sense of control, readability, comfort level, adaptability, sociality, and place-meaning given by the environment are all a part of the place experiences. To be "adaptable to the elders", we have to "understand the 
elders", and we must "entertain the elders" instead of "confining the elders". An adaptable community environment to the elders must be open, and provides a meaningful place for them: While improving the environment and living quality of the elders, their own enthusiasm to adapt shall be encouraged, and make sure that they catch up with the pace of the general information of the times. A community participatory urban atmosphere has to be created, the lines between boundary and regions have to be blurred, the overlapping of privacy and commonality has to be emphasized, scattered ancillary facilities must be arranged, accessible courtyard-style areas shall be formed, and the theme and features of the community shall be created. Small-block, dense road network and narrow road modes are appropriate to be adopted for the organization of the community - since such modes are proven to be superior to traditional large-block, discrete road network and wide road modes. Small-block mode enables the elders to access to the streets of neighboring communities on foot in a shorter time to use public facilities such as bus and stores.

Subjective experiences and cognitive feelings serve as the major approaches for the construction and evaluation of the adaptability to the elders of residence in traditional communities, which are difficult to carry out quantitative analysis of architectural performance indexes. System analysis engineering and other theoretical methods of other subjects can be introduced to achieve more subjective, accurate, scientific and systematic construction and evaluation of elderly adaptable facilities in an "open", "controllable" and "stable" manner(please refer to Fig.5). 


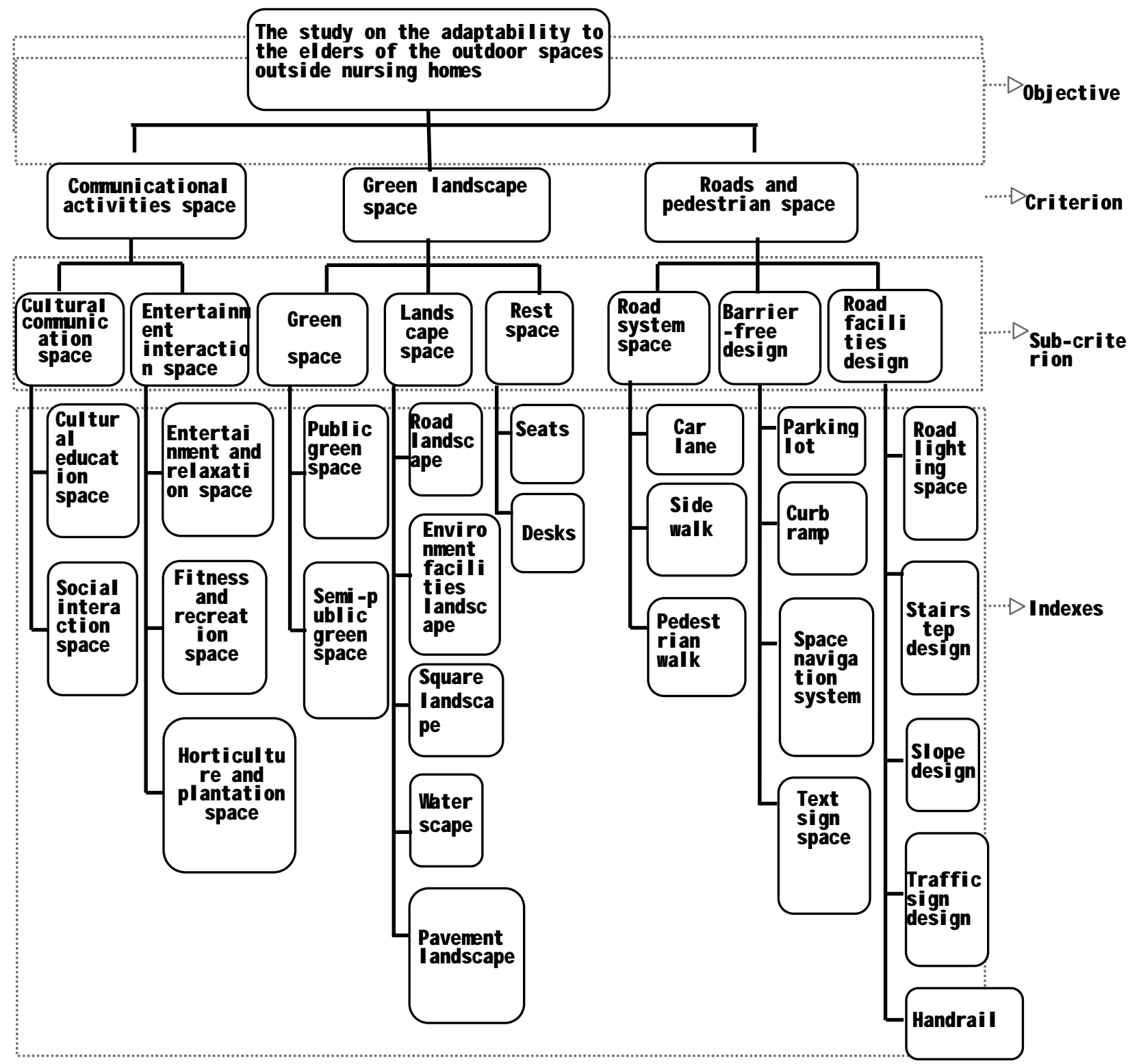

Fig.5 The hierarchical chart of the index system model of the adaptability to the elders of the public spaces outside nursing homes

The structural mode of an adaptable living space to the elders highlights the original living environment on the basis of built-in site location and site development, of which the space components include small scale multifunctional living system, dynamic social networking system, pedestrian paths, sign design and rest space design, a total of 6 parts.

1) Small scale multifunctional living system. An interactive environment between the nursing home and original living community is built to improve the environment quality of the living quarter. The existing elderly care institutions and facilities of the region are effectively integrated under the premise that the basic living conditions are met. The social elderly services resources are reasonably allocated to meet the living and care needs of different elderly groups in the residential quarter.

2) Dynamic social networking system. Including the networking within the region, between different social groups, and of groups of different ages. The elders are often quite familiar with all sorts of activities in the region since they live in the same place for years, and the quality of regional 
activities can be steadily improved with the help of their experiences. The networking range of the elders shall be expanded for regular and targeted networking, as well as positive organization and participation in various activities in the region so that they may have more opportunities to blend in the local society, and grasp social changes in time; meanwhile, the elders can be divided into different smaller social groups according to their own interests and health conditions, forming network with corresponding groups in society and participate in various activities on a regular basis. The networking between the elders and people of other ages shall be enhanced so that they may perceive recognition and respect from the society and become social resources that may still be useful and make contributions.

3) Pedestrian paths in the community. The maximum walking distance of healthy elders shall be controlled within 10 minutes and 450m. Long and straight pedestrian paths must be avoided, and circulating paths that are friendly, fun and provide opportunities to do physical exercises can be created to a certain extent.

4) Sign design in the community. The colors of design must be highly recognizable colors for the elders such as yellow and red, and the signs shall be helpful for the elders to locate and guide themselves as well as engage in social networking; the height of signs is recommended to be within 700 to $1,600 \mathrm{~mm}$, and the height of sighting line of those in wheelchair must be considered as well.

5) Rest space design for the elders. A rest space shall be set up every $50 \mathrm{~m}$ of the pedestrian system in a community for the aged. The benches shall be arranged in favor of the communications among the elders. "L", "M" and "U" shaped arrangements are recommended for the convenience of face-to-face and sitting-around scenarios.

6) The affective commitment and cultural belongingness of the elders. "Your environment shapes who you are", and that's why Chinese emphasize the philosophy of the unity of the nature and men. A place of affective and cultural commitment is place that nourishes the elders, and we have to pay close attention on the congruence and co-existence of landscape and people, the inherent connection between the nature and men, and a resonance between the figurative, perceivable and authentic experiences as well as the spiritual association ${ }^{[3]}$. It is necessary for a community to become a place where the elders "are peaceful, comfortable and entertained".

\section{Suggestions for the Adaptability to the Elders of Nursing Home itself}

Nursing home is the heart of the elderly services in a community, which provides a variety of services to the elders that are designed to promote health, enrich themselves, and entertain them, as well as a series of functions of short-term settlement, long-term settlement and life care; meanwhile, the main functions of built-in supportive services for the elders are mainly about the provision of information related to home care services and health-related guidance. 


\section{Buildings and space pattern}

Generally speaking, the total building area of a community nursing home is recommended to be within $10,000 \mathrm{~m} 2$, and buildings are recommended to be less than five floors. The buildings can be divided and arranged according to the evaluation of the physical conditions of those who live in them (daytime care, mid-term care, and long-term care). The first floor shall be left for elderly care if possible, offering convenience to the pickup and drop-off of those daytime care elders, and avoiding interference with the functions and atmosphere of those long-term care elders. The appearance of buildings shall be consistent with the buildings of their original living communities. The purpose of elderly care must remain unchanged and the confinement of the elders shall be avoided, while the identifiability and compliance with the adaptability to the elders must be retained. As for the plane design, a courtyard-style or circular-corridor-style are suitable in order to improve the cultural commitment of the elders as well as the versatility and conveniences (please refer to Fig.6 and Fig.7).

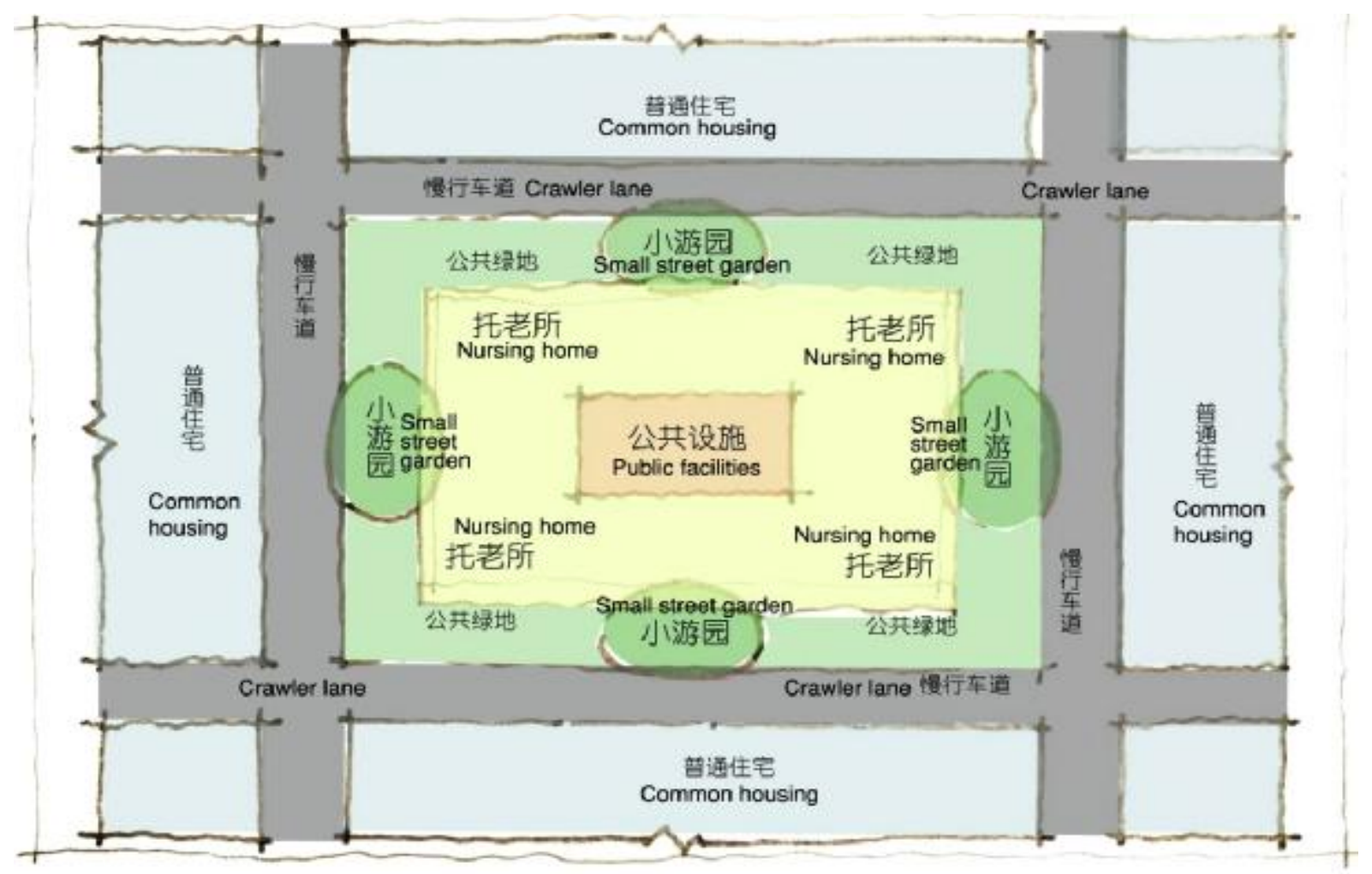

Fig.6 Floor plan of the nursing home 


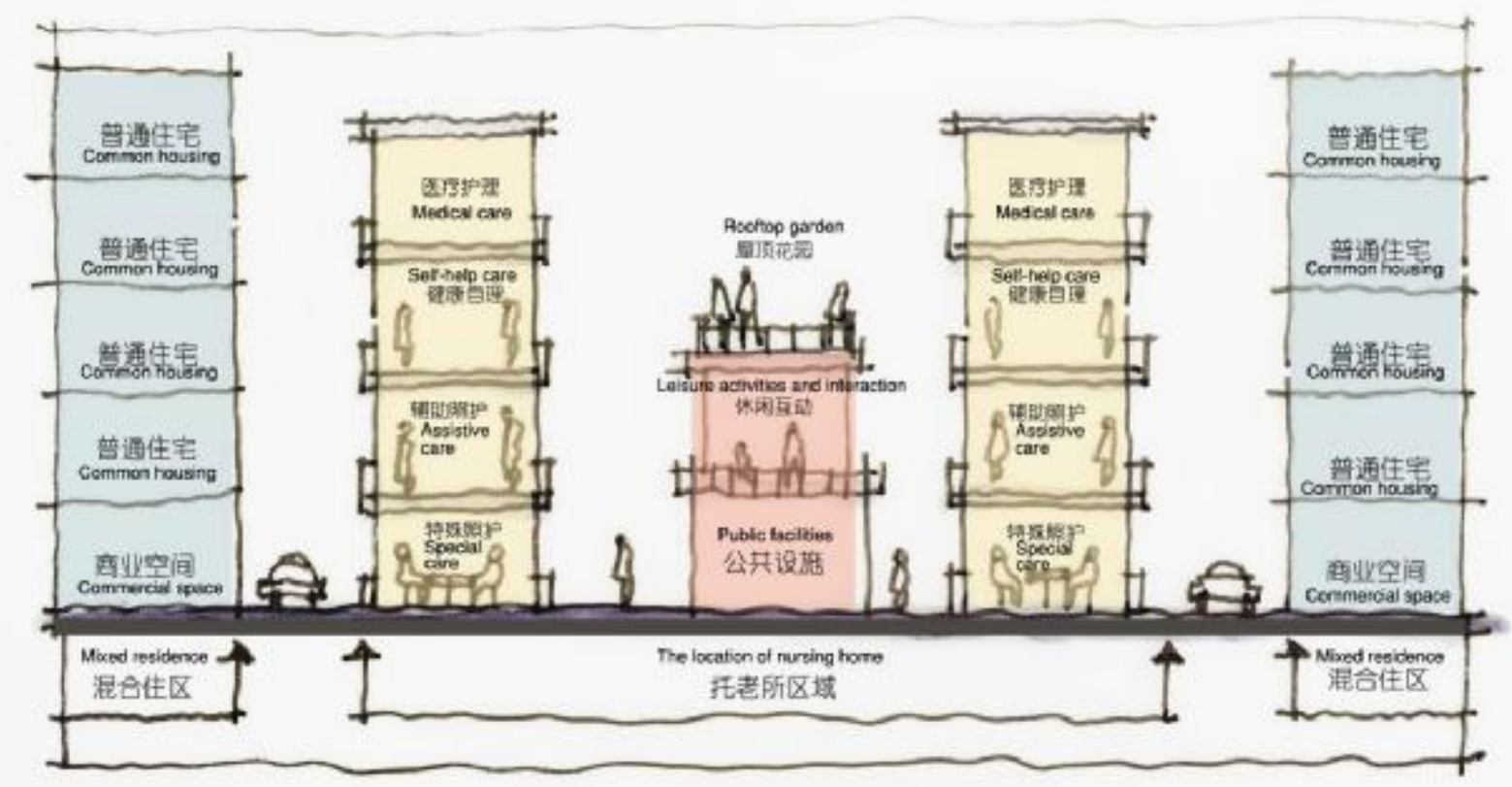

Fig.7 Vertical plan of the nursing home

Similarly, in terms of the adaptability to the elders of the buildings and the inside, systematic approaches such as AHP (Analytic Hierarchy Process) is recommended for the building of corresponding evaluation index system and empowerment calculation shall be carried out for indexes of different levels after the comparative analysis of existing relevant theories and standard models on the basis of relevant investigated results. Related functional indexes regarding the adaptability to the elders of community nursing home shall be fully refined and quantified in order to guide the construction of adaptable community nursing homes in the city (please refer to Fig.8). 


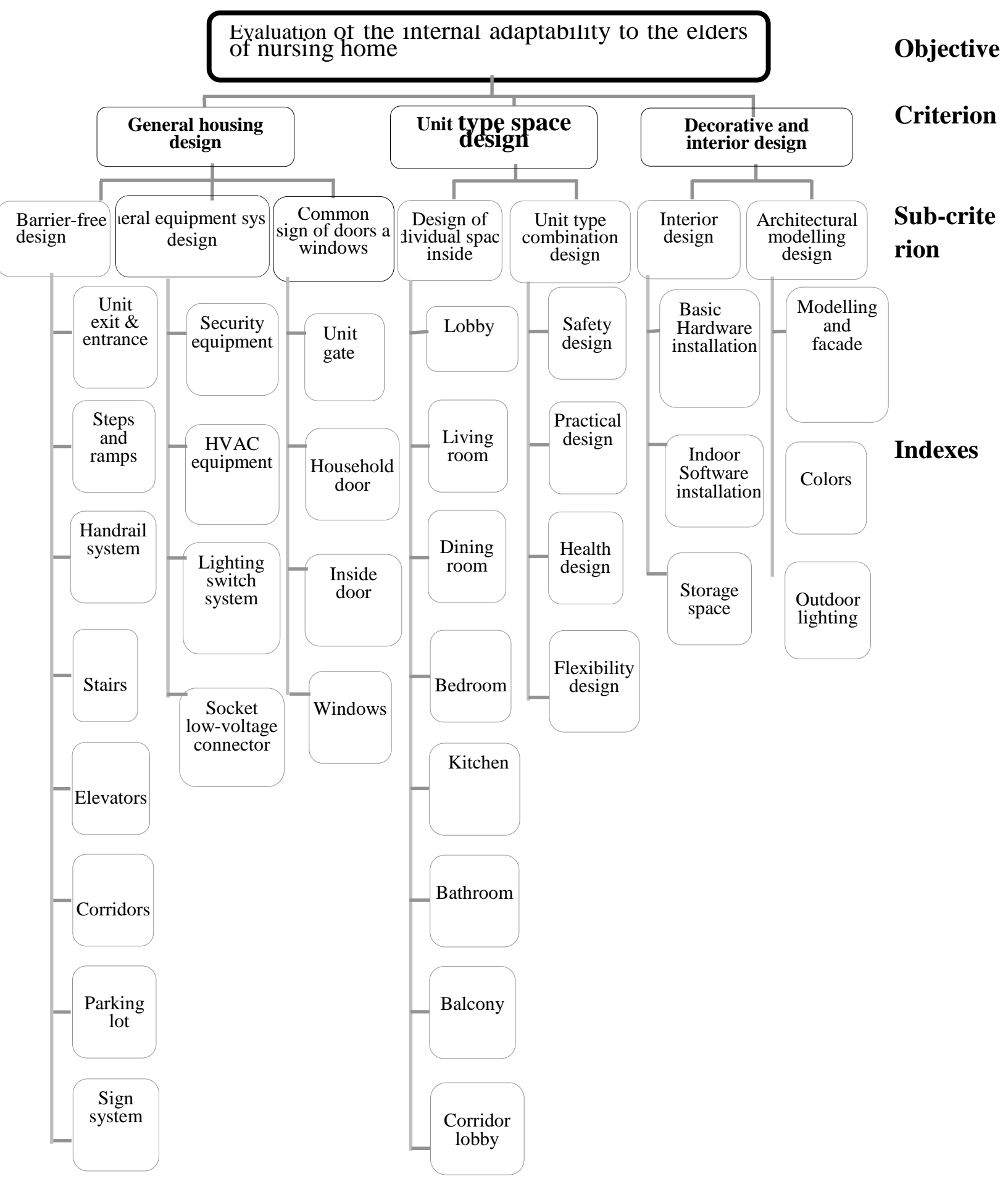

Fig.8 The hierarchical chart of the index system model of the adaptability to the elders of the internal spaces of nursing homes

The structure of functional space and spatial relations: The basic functional spaces inside a community nursing home are consisted of living rooms, management rooms and logistic rooms. Living rooms include living space (bedroom), public space (living hall, dining hall and reception 
hall), and bathroom space (toilet and shower room); management rooms include office and duty room; logistic rooms include kitchen, storage room, and laundry room. Besides, a community nursing home shall be equipped with outdoor activity space or next to the public activity space. Recreational rooms such as chess and card game rooms are necessary too since the aged inhabitants are greatly diversified ${ }^{[4]}$. Rehabilitation training room can be set up when the nursing home is equipped with professional instructors. The combination of the community nursing home and community medical service station, and community senior citizen center is an ideal setting. Public space shall be set up next to the living area in order to increase its utilization rate, such as a way from the living hall that leads to the bedrooms; the living hall shall be close to the dining hall or combined together to enhance the space flexibility and prevent the dining hall from being left unused outside the dining time; a public washroom and storage room shall be close to the living hall and dining hall for residents to go to toilet before dining and the replacement or adjustment of furniture and chairs; more living places shall be provided to the elders except for the common living hall, and some scattered spaces can be used as the place for relax or meeting with families. Adequate time for social networking is the extension and satisfaction of the elders' mental needs.

Suggestions for various functional spaces and object selection: In addition to sleeping, the bedroom is also the living space in where the majority of elders spend most of their time, as well as the place where they meet with families and even have meals. A bedroom must have excellent daylighting and view; the width of a double bedroom may not be less than $3.6 \mathrm{~m}$ and the spatial depth may not be less than $3.9 \mathrm{~m}$ so that the space in front of windows can be well used and needs of wheelchaired elders to meet guests; the height of windowsill is better to be controlled within $0.75 \mathrm{~m}$ for the convenience of overlook and other uses of it, and the width of it inside the casement may not be less than $0.35 \mathrm{~m}$. Most bedrooms can be double rooms with a certain portion of single rooms. The living hall must have excellent daylighting and outdoor landscape; the windowsill height may not be higher than $0.75 \mathrm{~m}$ in consideration of the height of sighting line of wheelchaired elders, and French windows are optional; a big living hall that accommodates more than 10 people can be divided into several sections by furniture arrangement so that the elders may choose to watch TV or other sections they prefer more conveniently; the objects shall be small and easy to replace and adjust (such as furniture and chairs etc.). The dining hall must have excellent daylighting; the windowsill height may not be higher than $0.75 \mathrm{~m}$ in consideration of the height of sighting line of wheelchaired elders; hand sink and small work platform can be set up in the dining hall for the elders to clean hands before dining and wash tableware afterwards. The distance between chairs in the reception hall may not be less than $1.3 \mathrm{~m}$ to meet the needs of wheelchaired elders to meet their families. An independent bathroom is preferred for the bedroom and an independent hand sink can be set up in the bedrooms where the elders in need of instrument assistance live to encourage them to pay more attention to personal hygiene; public bathrooms can be scattered and set up among every 10 people; the size of space for the convenience of nursing staff in the public bathrooms shall be taken into consideration. The shower room must provide the options of tub bath and showering; space for nursing staff shall be left at the sides of the bath chairs for showering; and at least 1 shower nozzle for every 6 people. The laundry room shall be next to the shower room $^{[5]}$. The presentation of space is subject to its applicability, and the materials and textures shall be natural and simple, the colors are preferably bright and warm light tones, and customization of colors is available if needed. Artificial lighting must be reasonable and conform to the use of senior citizens in terms of lighting method and color temperature. 


\section{Conclusions}

In conclusion, the study of the adaptability to the elders of aging in place is a regional and complicated task. As of now, most of the theoretical studies and application practices whether in China or foreign countries are still on the level of the adaptability design and in lack of the focus on systematic methodology, let alone a scientific, objective and all-round evaluation method and quantitative index system. Researchers have to lay their emphasis on the actual needs of aged users and consider questions in the general planning, then analyze the existing problems such as the composition of aged population, their needs for care and space resources through profound study of community planning; understand the forces and appeals involved or may get involved in the future; grasp the objectives of common development and provide space support for community nursing home services; put forward practical and viable action plans to further perfect community functions and service system; and propose an effective method to deal with the accommodation and service problems that emerged along with China's aging problem to provide good theoretical support and quantitative indexes for aging in place.

\section{Acknowledgments}

This paper is a staged achievement of the 2015 Humanities and Social Sciences Research Program of the Ministry of Education "A Study on Sketching Iconography for Environmental Design under the Perspective of Human Settlement Sciences" (Project Number 15YJC760109); a staged achievement of the 2015 Social Sciences Fund Program of Jiangsu "A Study on the Construction and Application of the Theoretical System of Sketching Iconography for Environmental Design" (Project Number 15YSB005); an achievement of the 2015 Educational Science planned topic of the " $12^{\text {th }}$ Five-Year Plan" "A Study on the New Model of Artistic Design Teaching and Teaching Control System - the Example of Environment Artistic Design" (Project Number D/2015/01/67); and an achievement of the 2015 Teaching Reform Task of Nanjing University of Science and Technology (2015-A-22).

\section{References}

[1] Verderbr, 5.\&D. Fine. "Architectural Environments for the Aged, 1965-2000[A]//Healthcare Architecture in an era of radical transformation. New Haven: Yale University Press (2000), 223-277.

[2] Barry C. Yang. Place Meaning: Aging in Place and Senior Housing [J], Time Architecture (2012), 6:58-63.

[3] Xu Wei. A Study on Sketching Iconography for Environmental Design under the Perspective of Urban Landscape Construction [J], Hundred Schools in Arts (2015), 2:171-173.

[4] Zhou Bo, Wang Hongyi, Lu Wei, Liu Jianjun, Li Tieli. Exploration of the Structural Mode of the Livable Space in Senior Residential Area [J], Special Issue of Academic Papers of Architectural Journal (2015), 14:95-98.

[5] Lin Wenjie et al. A Study on Space Design of Community Nursing Home based on Elderly Behavioral Patterns [J], Time Architecture (2012), 6:42-47. 